\section{Carcinoma Insular de Tireóide}

O objetivo dessa apresentação é discutir o Carcinoma Insular da Tireóide, uma forma rara de neoplasia com características clínicas e histológicas bastante peculiares. Inicialmente, será apresentado o caso seguido de uma breve discussão clínica. Posteriormente, serão discutidos aspectos histológicos e IHQs e os marcadores de agressividade desse tipo de tumor, seguindo-se uma discussão aberta com outros membros do serviço.

Unitermos: Carcinoma insular de tireóide; Carcinoma diferenciado de tireóide; Carcinoma Indiferenciado de Tiróide; Gene p53; IHQ de p53.

\section{APRESENTAÇÃO DO CASO}

Paciente feminina, branca, com 18 anos e história de aumento do volume cervical há 3 anos. Há 2 anos realizou ultrassonografia (USG) de tireóide que revelou aumento importante do lobo esquerdo às custas de nódulo sólido heterogêneo de $7 \times 5 \times 4 \mathrm{~cm}$ que se estendia em direção à fúrcula e comprimia, ligeiramente, a traquéia; não havia adenomegalia.

Nesta época, foi realizada punção aspirativa com agulha fina (PAAF) do nódulo e a citologia do material obtido foi sugestiva de carcinoma (CA) indiferenciado de tireóide. A paciente foi submetida à tireoidectomia total, em outro serviço, e o diagnóstico patológico da neoplasia foi de CA indiferenciado de pequenas células, variedade insular.

Após a cirurgia, a paciente recebeu radioterapia externa na região cervical e iniciou terapia com doses supressivas de L-T4 $(200 \mu \mathrm{g} /$ dia $)$. Na ocasião não foi realizada pesquisa de corpo inteiro com ${ }^{131}$ I (PCI-131I) e nem administrada dose ablativa de ${ }^{131} \mathrm{I}$. Um mês após o término da radioterapia notou a presença de nódulo na região da fúrcula, que aumentou progressivamente. Concomitantemente, iniciou quadro de astenia e perda de peso e, há 8 meses, desenvolveu dispnéia, tosse, dor torácica com piora da astenia e perda de peso.

Com essas manifestações, procurou o pronto socorro do Hospital das Clínicas da FMUSP onde foi realizado raio-X de tórax que revelou nódulo grande no pulmão esquerdo, nódulos esparsos nos dois campos pulmonares e velamento da base do pulmão direito. Foi submetida à tomografia computadorizada (TC) de tórax que confirmou nódulo de $10 \mathrm{~cm}$ no lobo esquerdo, vários nódulos em ambos os pulmões e gânglios mediastinais (figura $1 \mathrm{~A}$ ).

\section{caso especial}

\author{
Maria Adelaide A. Pereiva \\ Rosalinda Camargo \\ Geraldo Medeiros-Neto
}

Hospital das Clínicas da Faculdade de Medicina da Universidade de São Paulo (FMUSP), São Paulo, SP.

Recebido em 21/02/00

Revisado em 27/03/00 Aceito em 31/03/00

\footnotetext{
Responsável pela Apresentação: Maria Adelaide Albergaria Pereira

Responsável pela Discussão: Rosalinda Camargo e Geraldo Medeiros-Neto

Responsável pela Edição: Maria Adelaide Albergaria Pereira
} 

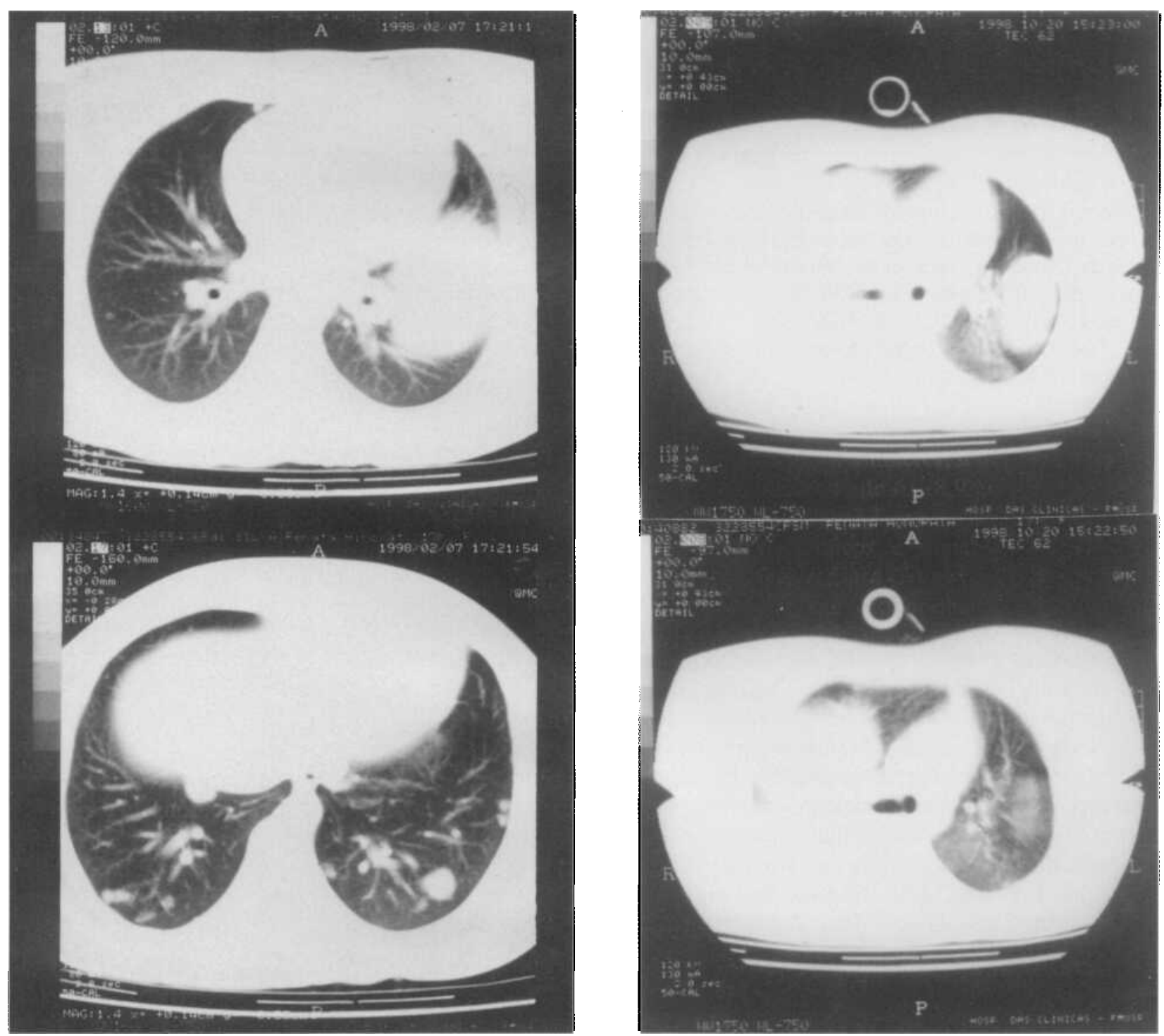

Figura 1 - Tomografias computadorizadas de tórax. A: volumosa massa com componente sólido e cístico, medindo $10 \times 7 \times 5 \mathrm{~cm}$ em lobo médio pulmão esquerdo e várias imagens nodulares em ambos os pulmões. B: 9 meses após, verifica-se crescimento de processo expansivo sólido em hemitorax direito medindo $16 \times 14 \times 17 \mathrm{~cm}$; não houve alteração da tumoração do lobo inferior E. Presença de derrame pleural.

Com o diagnóstico provisório de carcinoma metastático de tireóide, a paciente foi encaminhada para o Serviço de Oncologia do HCFMUSP, onde foi submetida a vários ciclos de quimioterapia com adriamicina, cisplatina e etoposide. Segundo informações fornecidas pelos oncologistas, houve pequena diminuição do nódulo da fúrcula e melhora dos sintomas respiratórios.

Dois meses após o início da quimioterapia, a paciente foi submetida a PCI com ${ }^{131}$ I que revelou captação intensa do traçador na base do pulmão direi- to e na região da fúrcula. Ainda assim, a paciente não recebeu dose terapêutica de radioiodo, sendo mantida em quimioterapia. Posteriormente, como houvesse progressão das metástases pulmonares e crescimento do nódulo cervical, foi suspenso o tratamento quimioterápico.

Há dois meses, paciente desenvolveu cefaléia holocraniana severa, acompanhada de vômitos e malestar e, há 3 dias, perda do campo visual temporal direito. Com esses quadro, foi internada no serviço de emergência da Neurocirurgia do HCFMUSP. Uma 


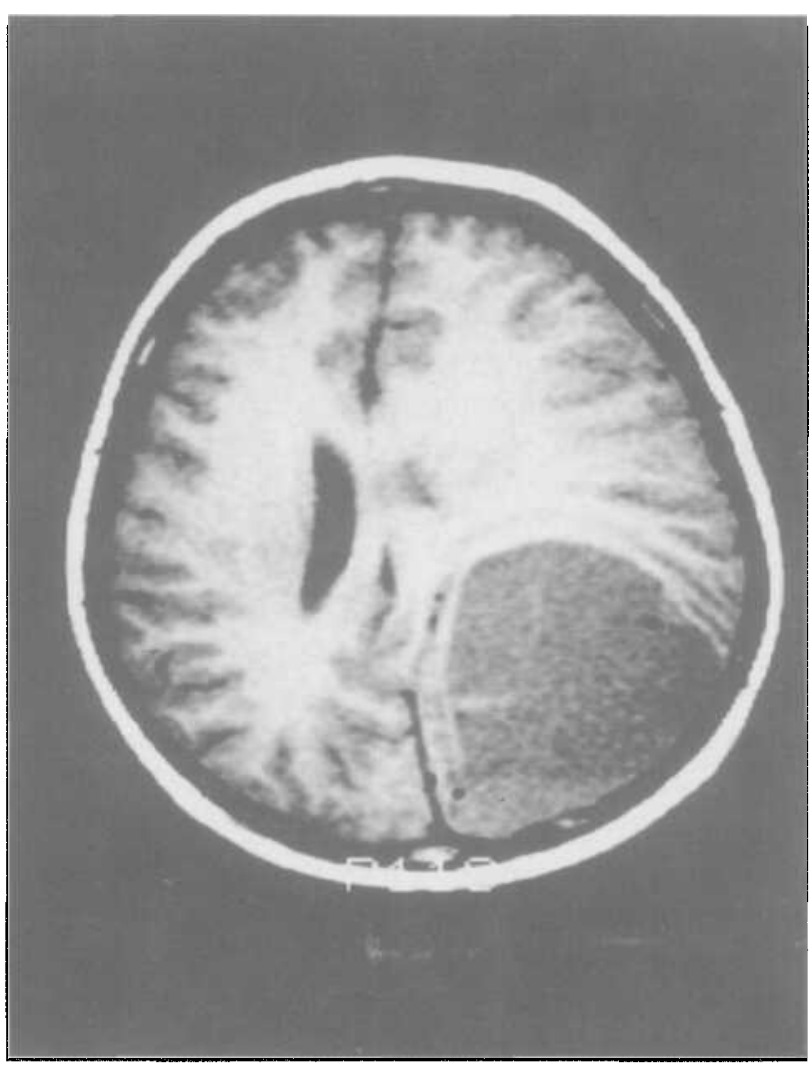

Figura 2 - Ressonância Magnética de Crânio: formação expansiva parieto-occipital E com hiposinal em T1. Edema perilesional causando importante efeito de massa, com desvio das estruturas da linha mediana para a D, com redução do VLE.

ressonância magnética (RM) revelou lesão cxpansiva em região occipital esquerda com edema peri-lesional importante, que comprimia o ventrículo lateral e causava deslocamento de todo o hemisfério dircito para o lado contra-lateral; havia captação irregular de contraste e a lesão mostrava-se hipercaptante em T2 (figura 2).

Durante a internação, paciente cvoluiu com convulsões tônico-clônicas generalizadas, anisocoria e rebaixamento do nível de consciência, sugerindo quadro de herniação cerebral. Foi submetida a neurocirurgia de urgência para retirada da massa cerebral. Nesta ocasião, o Serviço de Endocrinologia solicitou cstudo histológico e IHQ da lesão cerebral. O exame anátomo-patológico, a ser comentado posteriormente, foi CA indiferenciado e a imunohistoquímica (IHQ) foi positiva para tireoglobulina e p53.

Após a cirurgia, houve melhora importante do quadro neurológico e a paciente foi transferida para o Serviço de Endocrinologia do HCFMUSP. Na ocasião, ao exame físico revelava $\mathrm{cm}$ regular estado

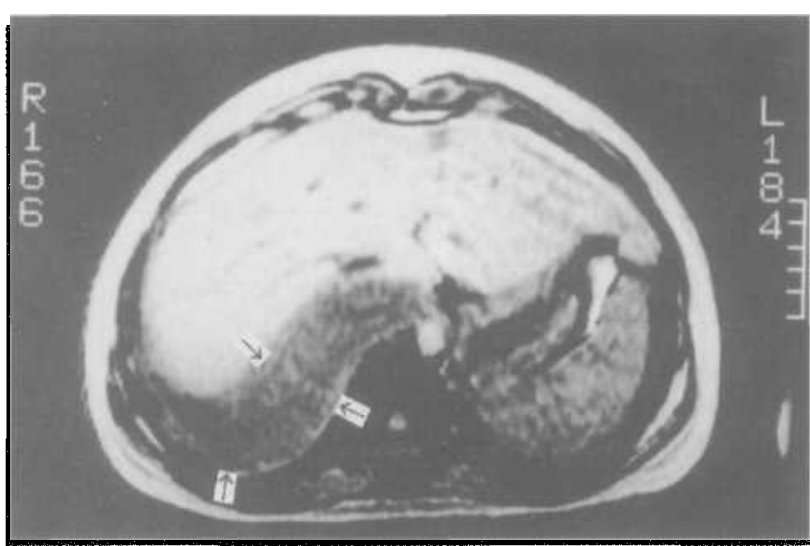

Figura 3 - Ressonância Magnética de Abdome: formação extra-peritoneal que contorna o figado lateral e inferiormente. Provável extensão da lesão neoplásica do tórax em direção ao abdome.

geral, descorada e discretamente taquipnêica. A tireóide não era palpável mas havia nódulo de $5 \mathrm{~cm}$ na região da fúrcula, indolor, endurecido e aderido a planos profundos. Havia diminuição do murmúrio no terço médio inferior do hemi-tórax direito e na base do hemi-tórax esquerdo. A avaliação laboratorial geral não revelava apenas anemia normocítica-normocrômica, leucócitos no limite inferior do normal e aumento discreto de enzimas hepáticas $[\mathrm{TGO}=38 \mathrm{U} / \mathrm{L}(10 \mathrm{a}$ $30), \mathrm{TGP}=45 \mathrm{U} / \mathrm{L}(10$ a 36$), \gamma-\mathrm{GT}=486 \mathrm{U} / \mathrm{L}(7 \mathrm{a}$ 32) e fosfatase alcalina $=292 \mathrm{U} / \mathrm{L}(32$ a 104) $]$.

A avaliação laboratorial tireoideana está resumida na tabela 1 : mesmo com TSH suprimido às custas de doses altas de hormônio tircoideano, os níveis de tireoglobulina sérica mantinham-se extremamente elevados. Na ocasião da cirurgia cercbral e na ausência de hormônio tircoideano (suspenso pela intenção de se administrar dose terapêtutica de ${ }^{131} \mathrm{I}$ ) a tireoglobulina sérica atingiu níveis de $25.000 \mathrm{ng} / \mathrm{dl}$.

Novo raio-X e TC de tórax mostravam expansão da lesão na base do pulmão direito, porém sem progressão da lesão esquerda (figura 1B). O USG de abdome revelou massa extra-peritoneal, junto ao figado, tendo-se suspeitado de metástases em parede

Tabela 1 - Evolução da tireoglobulina, T4 livre (T4L) e TSH.

\begin{tabular}{lllll}
\hline data & $\begin{array}{l}\mathrm{T}_{4} \text { livre } \\
(\mathrm{ng} / \mathrm{dl})\end{array}$ & $\begin{array}{l}\mathrm{TSH} \\
(\mu \mathrm{U} / \mathrm{ml})\end{array}$ & $\begin{array}{l}\text { Tireoglobulina } \\
(\mathrm{ng} / \mathrm{ml})\end{array}$ & $\begin{array}{l}\mathrm{L}-\mathrm{T4} \\
(\mu \mathrm{g} / \mathrm{dia})\end{array}$ \\
$16 / 2 / 1998$ & 1,2 & 0,3 & 24,8 & 200 \\
$18 / 11 / 1998$ & 1,9 & 0,2 & 134 & 200 \\
$9 / 12 / 1998$ & 0,5 & 30 & 24110 & - \\
$15 / 12 / 1998$ & 0,5 & 74 & 25060 & - \\
V.R.: & $0,6-1.54$ & $0,5-4,2$ & $<20$ & \\
\hline
\end{tabular}




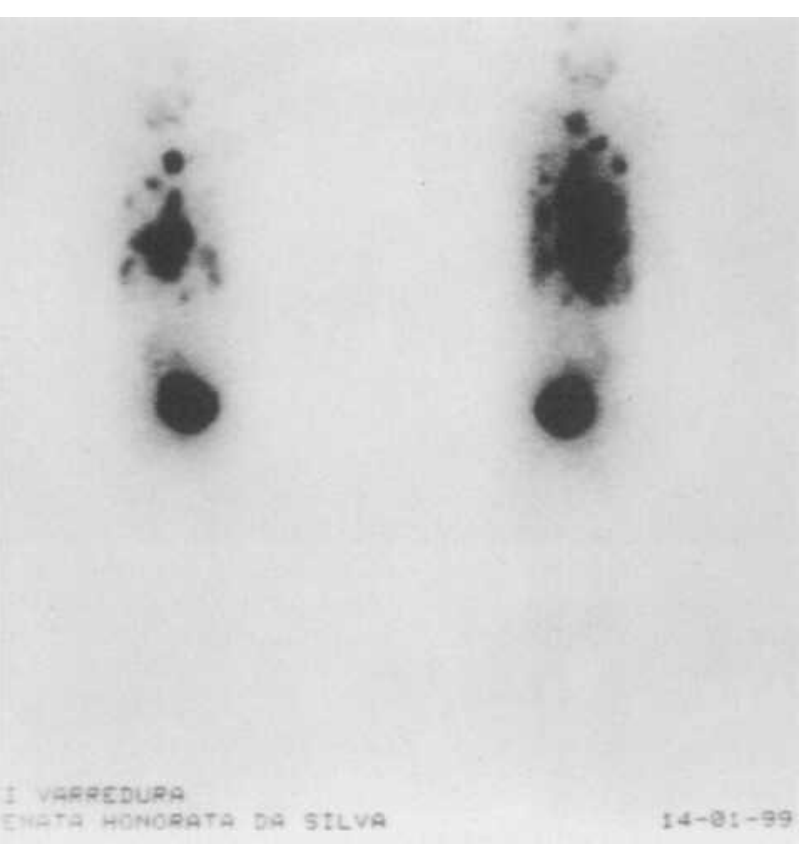

Figura 4 - Pesquisa de corpo inteiro com $131 \mid(P C|-131|)$ : Acúmulo anormal do radiofarmaco em grau acentuado em ambos os pulmões, em região da fúrcula e no abdome.

abdominal. A RM de abdome revelou que se tratava de expansão da lesão torácica, estendendo-se em direção ao abdome, contornando lateral $\mathrm{e}$ inferiormente o figado (figura 3). Nessa ocasião, optou-se por tratamento com ${ }^{131}$ I, sendo a paciente então mantida sem hormônio tireoideano. A PCI-131I, demonstrou expansão do quadro metastático (figura 4), com piora importante do quadro respiratório e o raio-X de tórax mostrando progressão das lesões pulmonares com grande derrame pleural à direita. A paciente evoluiu com insuficiência respiratória e faleceu antes de receber a dose terapêutica de ${ }^{131} \mathrm{I}$.

\section{DISCUSSÃO CLÍNICA:}

\section{Dra. Maria Adelaide Albergaria Pereira}

O CA insular de tireóide é um tumor raro representando cerca de $5 \%$ a $10 \%$ dos carcinomas de tireóide. Ocorre com maior freqüência em zonas de deficiência endêmica de iodo explicando, talvez, sua maior freqüência na Europa e a raridade com que é relatado na literatura Americana. Esse tumor, descrito inicialmente por Langhans em 1907 (I), foi posteriormente estudado por Carcangiu e col. (2) que descreveram 25 casos a partir da revisão de todas as lâminas de CA de tireóide que haviam sido estudadas pelo departamento de patologia da Universidade de
Florença. Esses autores chamaram a atenção para as particularidades histopatológicas e para o comportamento biológico desse tipo de tumor, que passaram a denominar de carcinoma pouco diferenciado da tireóide, forma insular.

A principal característica microscópica é que as células tumorais são pequenas e uniformes, formando aglomerados sólidos semelhantes às ilhotas pancreáticas; observa-se, também, invasão de cápsula e vasos, presença de atividade mitótica em grau variável e, freqüentemente, focos de necrose. Metástases para gânglios regionais, pulmões e ossos são comuns e responsáveis pelo óbito.

A partir de 1984, surgiram alguns trabalhos, principalmente na Europa, descrevendo casuísticas desse tipo de tumor (3-6). Como todo carcinoma de tireóide, há predomínio no sexo feminino, e faixa etária de maior prevalência em torno de $\mathbf{5 5}$ anos, embora a idade possa variar de 16 a 69 anos. Segundo a maioria dos autores, o tamanho do tumor original, é superior a $4 \mathrm{~cm}$. Apesar do estadiamento mostrar-se variável de acordo com os autores, geralmente a doença encontra-se em estádio avançado por ocasião do diagnóstico: $16 \%$ a $74 \%$ dos pacientes apresentam a doença restrita à tireóide; $11 \%$ a $35 \%$ apresentam metástases ganglionares e $15 \%$ a $68 \%$ metástases à distância. Vários estudos chamam a atenção para o fato de que metástases à distância muitas vezes se associam à metástases ganglionares regionais ou mediastinais. Este é o primeiro ponto que diferencia esse tipo de CA do folicular clássico, o qual raramente evolui com acometimento ganglionar regional.

Quanto à evolução dos pacientes, verifica-se alto índice de recidiva ( $41 \%$ a $83 \%$ ) que ocorre, em geral, nos primeiros 3 anos do pós-operatório. Em seguimento médio de 5 anos observa-se, também, elevada taxa de óbito ( $10 \%$ a $44 \%$ ) causado pelo tumor (tabela 2). Portanto, trata-se de tumor com comportamento agressivo, bastante diferente do comportamento habitual dos CAs diferenciados de tireóide. A taxa de recidiva 10 anos após a cirurgia, para os carcinomas papilífero e folicular de tireóide está em torno de $5 \%$ e de $25 \%$, respectivamente $(7)$, número bem inferior ao observado na variedade insular do CA folicular de tireóide. A sobrevida com esse tipo de neoplasia também é inferior à sobrevida dos pacientes com CA diferenciado de tireóide. Mais uma vez, esse tumor mostra comportamento biológico muito mais agressivo do que aquele apresentado pelos Cas papilíferos e foliculares clássicos, sem ter, porém, evolução tão catastrófica como o CA anaplásico que, geralmente, leva a óbito em menos de 6 meses após o diagnóstico. 
Tabela 2 - Carcinoma Insular de tireóide: Evolução Clínica.

\begin{tabular}{llll}
\hline Referência & $\begin{array}{l}\text { Seguimento } \\
\text { Média/ (Variação) }\end{array}$ & Recorrência & Óbito* \\
\hline 2 & $\begin{array}{l}3,9 \text { anos } \\
(1-8 \text { anos) }\end{array}$ & $66 \%$ & $44 \%$ \\
3 & $\begin{array}{l}4,6 \text { anos } \\
(0,1 \text { a } 16,5 \text { anos) }\end{array}$ & $41 \%$ & $17 \%$ \\
4 & $\begin{array}{l}4 \text { anos } \\
\text { (1a 12anos) }\end{array}$ & - & $10 \%$ \\
5 & $\begin{array}{l}9 \text { anos } \\
(0,25 \text { a } 19 \text { anos) }\end{array}$ & $48 \%$ & $37 \%$ \\
6 & 4,8 anos & $83 \%$ & $17 \%$ \\
\hline
\end{tabular}

* óbito decorrente do tumor

Em $48 \%$ dos casos, as metástases ocorrem para gânglios cervicais e mediastinais, $20 \%$ para pulmão e $25 \%$ para osso. Em geral, o tecido metastático capta iodo radioativo, permitindo o seu uso no tratamento da neoplasia. Raramente são descritas metástases cerebrais, como a que ocorreu nesta paciente. Em 1997, foi publicada a descrição de dois casos de carcinoma insular em pacientes de 15 e 16 anos; uma delas mostrou comportamento clínico semelhante ao apresentado pela nossa paciente, inclusive com a presença de metástases cerebrais. Os autores chamam a atenção para a raridade desse tipo de tumor em crianças (8).

Portanto, tanto do ponto de vista morfológico como biológico, o carcinoma insular de tireóide situase entre o CA diferenciado de tireóide e o anaplásico. $\mathrm{Em}$ função desse comportamento mais agressivo, são feitas algumas recomendações para o seu tratamento: 1) Tireoidectomia total e remoção ganglionar profilática, à semelhança do que é feito para o CA medular de tireóide; 2) Administração de dose ablativa de iodo radioativo após a cirurgia (mínimo de $100 \mathrm{mCi}$ ); 3) Seguimento semestral obrigatório com exame clínico da região cervical, USG de tireóide e determinação dos níveis de tireoglobulina. Realização de PCI anual durante os 3 primeiros anos de seguimento. Qualquer elevação da tireoglobulina deve motivar a realização de PCI com 131-I. Se a PCI for negativa com dose traçadora deve-se fazer nova PCI após a administração da dose terapêutica de radioiodo; 4) Administrar sempre dose terapêutica de iodo radioativo para o tratamento de metástases captantes; 5) Radioterapia externa da região cervical está indicada nos casos invasivos, o que é razoavelmente freqüente nesse tipo de tumor. A quimioterapia tem valor duvidoso e incerto no tratamento dessa neoplasia.

Poderíamos chamar a atenção para as seguintes falhas que aconteceram no seguimento dessa paciente:
1) Inicialmente ela foi submetida à tireoidectomia total, mas não existe relato de remoção ganglionar profilática; 2) Não realizou PCI com ${ }^{131}$ I e não recebeu dose ablativa de 131 ; 3 ) Quando foi realizada a PCI com ${ }^{131} I$, dois anos após a cirurgia, ela não recebeu dose terapêutica, apesar da captação positiva. Embora não possamos garantir que medidas terapêuticas corretas teriam mudado a evolução dessa paciente, chamamos a atenção para estes equívocos na condução do tratamento.

\section{EXAME ANÁTOMO-PATOLÓGICO: Dra. Rosalinda Camargo}

O carcinoma insular da tireóide é um CA epitelial agressivo, classificado como pouco diferenciado. Sua descrição sistemática, conforme já mencionado, foi feita pela Dra. Maria Luiza Carcangiu, patologista italiana que chamou a atenção para as características histológicas desse tipo de tumor: apresenta-se formando ilhas de células (como se fossem as ilhotas do pâncreas) e as células são pequenas, possuindo núcleos pequenos e uniformes com citoplasma escasso (2). Na figura 5 pode-se ver corte histológico do tumor original, que tivemos a oportunidade de rever: trata-se de tumor sólido composto por ilhas de células, com núcleos pequenos e citoplasma escasso. Os núcleos são hipercromáticos, com cromatina grosseira e irregular, mas são todos do mesmo tamanho. São freqüentes as áreas de necrose e figuras de mitose. $\mathrm{O}$ arranjo das células em ilhotas é muito característico. A histologia do tumor cerebral foi semelhante à do tumor original. $\mathrm{O}$ estudo IHQ deste material mostrou

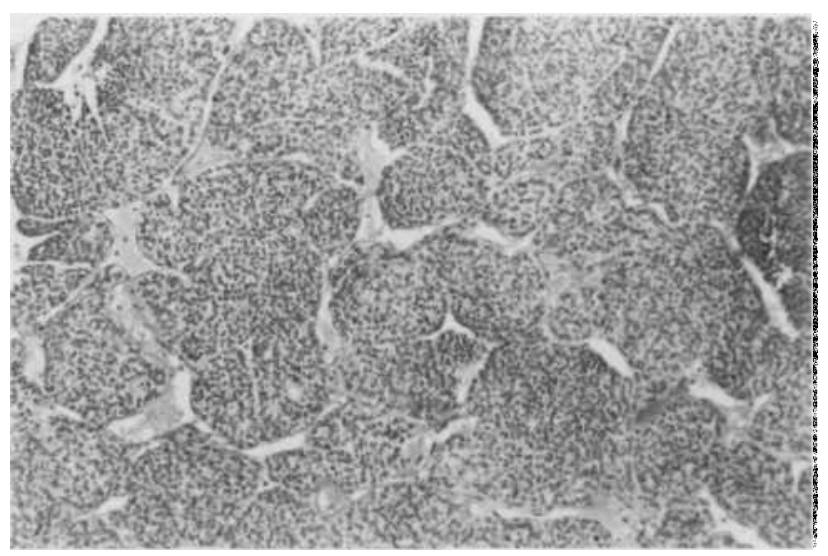

Figura 5 - Microscopia Óptica de Carcinoma Insular de Tireóide (coloração hematoxilina eosina; aumento 40X): tumor sólido composto por ilhas de células, com núcleos pequenos e hipercromáticos e citoplasma escasso. 


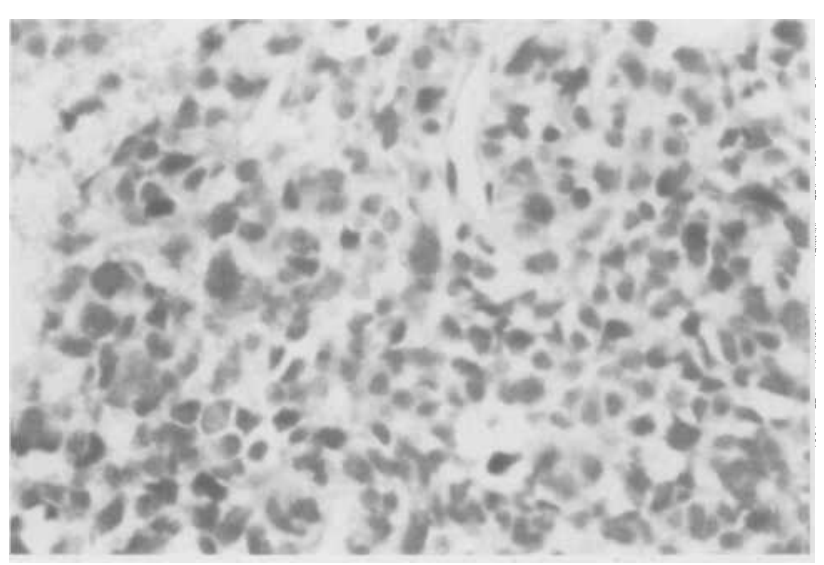

Figura $6-\mathrm{H} \mathrm{HQ}$ para p53 em metástase cerebral (aumento 400X): IHQ fortemente positiva para p53.

positividade para tireoglobulina e p53, confirmando a origem tireoideana do tumor $\mathrm{e}$ sua intensa agressividade (figura 6). Os CAs bem diferenciados da tireóide praticamente não expressam ou expressam em porcentagem mínima das células tumorais a proteína p53, ao contrário do carcinoma anaplásico, no qual a expressão desses antígenos é intensa. A metástase cerebral da paciente expressou claramente o antígeno p53 em mais de $70 \%$ das células.

A variedade insular do carcinoma de tircóide foi muito confundida com os CAs indiferenciados de tireóide de pequenas células. Hoje é classificado separadamente, apresentando comportamento biológico intermediário entre o CA diferenciado e o anaplásico de tircóide. Alguns autores consideram que esses tumores podem ter origem em CAs bem diferenciados de tireóide, folicular ou papilífero, cujas células sofrem mutação, tornando-se mais agressivos. Alguns CAs insulares têm células características de CA papilífero, com núcleos vazados e inclusões intranucleares e células com núcleos pequenos em arranjo insular.

\section{AGRESSIVIDADE TUMORAL E MUTA- ÇÃO NO GENE P53: \\ Prof. Dr. Geraldo Medeiros-Neto}

O gene p53 está localizado no braço curto do cromossomo 17 e consiste de 11 exons codificadores que determinam a produção da proteína nuclear p53, a qual é capaz de inibir a proliferação e a transformação celular. Portanto, essa proteína teria a função de controlar o crescimento celular, fazendo com que esta atividade fique dentro de certas proporções, definidas pela biologia de determinado órgão ou sistema envolvido. Mutações do gene $\mathrm{p} 53$ podem provocar crescimento celular excessivo e podem ocorrer em duas condições: na primeira, ocorre perda dos dois alelos do gene p53, com ausência do gene e da produção da proteína. A falta da proteína p53 provoca crescimento celular completamente descontrolado. Numa segunda condição, que é a alteração mais freqüentemente encontrada na biologia dos tumores, ocorre uma mutação autossômica dominante em um alelo do gene, determinando a produção de proteína p53 anômala. Essa molécula mutante possui vida média mais prolongada sendo funcionalmente incapaz de exercer atividade supressora de crescimento celular e pode ser utilizada como marcador de agressividade tumoral.

Os estudos IHQs para a pesquisa da proteína p53 $\mathrm{cm}$ tumores utilizam anticorpos que marcam a porção $\mathrm{N}$ terminal tanto da p53 nativa como da mutante. A proteína nativa normal tem uma vida média muito curta e este fato impede, parcialmente, que a reação antígenoanticorpo se expresse no estudo IHQ. Por outro lado, a proteína mutante, embora não tenha capacidade frenadora normal sobre o crescimento celular, possui vida média mais prolongada, permitindo que essa reação se manifeste nos estudos de IHQ. Portanto, as células com a mutação autossômica dominante no gene p53 têm IHQ positiva para o p53, enquanto as células sem esta mutação têm IHQ negativa.

Como já foi dito, o CA de tireóide com componente insular tem pior prognóstico do que os CAs bem diferenciados de tireóide. Este fato foi bem demonstrado em uma revisão clínico-patológica, conduzida no Japão por Sasaki e col. (9), que estudou a evolução pós-cirúrgica de 2.460 pacientes portadores de CA de tireóide; foi visto que os portadores de tumores com componente insular têm taxa de mortalidade maior do que aqueles portadores de Cas clássicos, papilífero ou folicular. Mutações no p53 poderiam estar envolvidas na maior agressividade desses tumores e é muito interessante comparar a freqüência com que elas ocorrem nos CAs bem diferenciados com aquela que ocorrem nos insulares.

Estudos IHQs clássicos utilizando anticorpos tradicionais, revelavam mutações em pequena porcentagem, cerca de $\mathbf{5 \%}$, dos CAs papilíferos e foliculares. Em 1998, pesquisadores dinamarqueses, com o apoio da empresa DAKO, desenvolveram um anticorpo recombinante capaz de reconhecer com maior clareza a proteína p53 mutante. Estudos IHQs com este novo anticorpo foram realizados em tecidos de CA diferenciado de tireóide de 212 pacientes (10); cram contados 500 núcleos e se obtinha um índice de positividade igual ao número de células positivas sobre o número de células estudadas. 
Observaram que 22 (10\%) tumores tinham IHQ positiva para p53 e que o índice de positividade médio foi de $17,4 \%$. A porcentagem de positividade, com o anticorpo recombinante é relativamente alta, se compararmos com os dados anteriores da literatura. Esses pacientes foram acompanhados por um período médio de 10,2 anos $(7,7$ a 25,4 anos) tendo-se verificado que a sobrevida era significativamentc maior nos pacientes com p53 negativo. Os pacientes com IHQ positiva foram divididos $\mathrm{cm}$ dois grupos: $\mathrm{com}$ indice de positividade para o p53 maior ou menor que $17,4 \%$. Observou-se que, aqueles com um alto índice de positividade ( 4 pacientes) apresentam pior prognóstico, com óbito ocorrendo 1 a 5 anos após o diagnóstico. Os 18 pacientes com valores entre $0 \% \mathrm{e}$ $17,4 \%$, mostraram taxa de sobrevida intermediária entre os que apresentam IHQ negativa e aqueles com IHQ fortemente positiva. Portanto, os autores chamam a atenção para o fato de que a presença do p53 é marcador de prognóstico mais grave e a agressividade do tumor é tanto maior quanto maior o número de células com mutação no gene p53.

Esse 1999, investigadores japoneses pesquisaram mutações no gene p53 em carcinoma insular de tireóide (11), fazendo o estudo IHQ para p53 utilizando anticorpo recombinante e utilizando uma técnica de estudo de biologia molecular conhecida como polimorfismo conformacional de fita simples ( $P C R-S S C P=$ polymerase chain reaction-based singlestrand conformation polymorphism). Foram estuda dos tecidos de 46 CAs insulares de tireóide: a partir do bloco de parafina era extraído o DNA e os exons $5,6,7$ e 8 eram amplificados por reação dc polimerase em cadeia. Esses exons foram escolhidos porque $98 \%$ da mutações descritas estão nessa localização. O estudo completo foi possível em 37 dos 46 casos e observou-se que $14(38 \%)$ apresentavam mutações no gene p53; a freqüência de IHQ positiva foi de $53 \%$, principalmente em áreas de componente insular do carcinoma e não nas áreas vizinhas de CA bem diferenciado. Os autores chamam a atenção para casos em que a IHQ foi positiva e a mutação não foi encontrada, bem como para casos em que, apesar de ser identificada uma mutação, a IHQ era negativa. Se somarmos o número de IHQ positiva com o número de mutações encontradas no gene do p53, o total de pacientes que apresentam alterações no p53 seria maior e atingiria $64 \%$ de todos os CAs Insulares estudados. Os autores concluem que mutações no p53 ocorrem com maior freqüência nos CAs com componente insular do que nos tumores bem diferenciados. Esse trabalho tam- bém teve o grande valor de nos indicar que existem duas metodologias para avaliar mutações no gene p53: a IHQ (se possível com a utilização do anticorpo recombinante) e a PCR-SSCP.

Podemos concluir que alterações genéticas têm papel importante e decisivo no comportamento clínico agressivo do CA com componente insular. A importância da identificação da mutação do $p 53$ reside no fato de que a sua presença é um fator determinante do prognóstico. Pacientes com essa mutação têm prognóstico pior do que aqueles sem a mutação.

Para o futuro, mutaçōes do p53 devem ser pesquisadas, por métodos de IHQ, em todos os CAs de origem folicular de tireóide. Aqueles com positividade nesse exame devem ser submetidos à investigação molecular criteriosa à procura de mutações definidas nos exons do gene p53. Se esses estudos forem feitos em material obtido da cirurgia ou, preferencialmente, da PAAF podemos identificar os pacientes com pior prognóstico e realizar tratamento mais radical.

\section{DISCUSSÃO ABERTA}

Dr. Daniel Giannella Neto (Professor Livre Docente do Serviço de Endocrinologia e Metabologia do HCFMUSP):

É importante chamar a atenção para o fato de que o gene p53, envolvido nos mecanismos de reparo do DNA, está relacionado com vários canceres, tendo sido descrito primeiramente nos tumores de cólon familiares. Gostaria de perguntar ao Prof. Medeiros se o anticorpo recombinante é específico para o mutante?

Dr. Geraldo Medeiros-Neto (Professor Associado da Disciplina de Endocrinologia e Metabologia da FMUSP):

$O$ anticorpo não é específico e reconhece tanto o p53 nativo como o mutante.

Dr. Marcello Delano Bronstein (Professor Livre Docente do Serviço de Endocrinologia e Metabologia do HCFMUSP):

Dra. Adelaide, achei estranho que na PCI-131 I a imagem no lobo esquerdo do pulmão não está proporcional ao seu tamanho. Quando você se refere a menor sobrevida dos pacientes com a forma Insular, foram comparados pacientes submetidos ao mesmo tipo de tratamento?

Dr. Geraldo, o estudo do p53 com essas duas técnicas propostas já foi feito para os CAs indiferenciados? 
Dra. Maria Adelaide A. Pereira (Médica Assistente Doutora do Serviço de Endocrinologia e Metabologia do HCFMUSP):

A lesão pulmonar no lobo esquerdo não foi progressiva e permaneceu do mesmo tamanho na evolução da paciente. Ela já estava presente quando a paciente iniciou a quimioterapia e os oncologista afirmam que, inicialmente, houve melhora do quadro respiratório após os primeiros ciclos de quimioterapia. Talvez tenha havido um efeito da medicação sobre esta lesão e por isso sua captação tenha sido menor. Era um lesão com componente necrótico e isto poderia também ser responsável pela menor captação de iodo. Os trabalhos não deixam claro qual a porcentagem de pacientes que foram submetidos a ${ }^{131}$ I ou à quimioterapia. Aparentemente, a maior parte recebeu iodo já que os autores chamam a atenção para o fato de que as metástases, em geral, captam iodo e produzem tireoglobulina, embora algumas não sejam captantes. De qualquer forma, é sempre evidente que a presença de metástases é maior nos CAs insulares e seu prognóstico é pior do que os CAs bem diferenciados.

\section{Dr. Geraldo Medeiros-Neto:}

A Dra. Rosalinda comentou que a IHQ para p53 costuma ser fortemente positiva nos CAs indiferenciados ou anaplásicos, mesmo quando realizado com o anticorpo tradicional. Temos o caso de uma paciente com bócio disormônio-genético (Síndrome de Pendred) que desenvolveu forma muito agressiva de tumor metastático. A lâmina revelou que uma porção do tumor era de CA folicular diferenciado e que outra era de tumor anaplásico. A IHQ, para tireoglobulina e p53, revelava expressão dessa última proteína apenas na porção indiferenciada do tumor e da tireoglobulina somente na porção diferenciada do tumor. Aparentemente, quanto mais indiferenciado o tumor maior é a expressão do p53 mutante. Não conheço nenhum trabalho no qual tenha sido estudada mutação do p53 pelas técnicas, mais recentes, às quais nós nos referimos.

Dr. Nicolau Lima Neto (Médico Assistente Doutor do Serviço de Endocrinologia e Metabologia do HCFMUSP):

Qual a dose terapêutica de iodo radioativo que foi recomendada? Alguns autores recomendam doses de 600 a $800 \mathrm{mCi}$ para o tratamento de casos graves, como esse que foi apresentado. Considero que doses menores do que essas não seriam adequadas.

Dra. Maria Adelaide A. Pereira:

Essa paciente iniciou seu acompanhamento no Serviço de Endocrinologia num estágio avançado de sua evolução e em função disso não foi possível o tratamento com iodo radioativo. Nós tínhamos proposto a administração de $300 \mathrm{mCi}$, que você está considerando uma dose insatisfatória. A dose média recomendada para metástases é de 200 a $300 \mathrm{mCi}$. Não sei dizer se uma dose de $600 \mathrm{mCi}$ seria melhor. De qualquer forma, a nossa paciente nunca recebeu a dose, porque faleceu nesse intervalo.

Dr. Wilian Nicolau (Professor Associado da Disciplina de Endocrinologia e Metabologia da FMUSP):

Uma conduta heróica, que poderia ter sido adotada nesse caso, seria a coleta de medula da paciente e a posterior administração de doses extremamente altas de 131 I, da ordem de 1 a 2 Ci. Gostaria de lembrar que temos dois tipos de metástases pulmonares: as difusas para as quais a administração de iodo radioativo pode ser mais perigosa, já que o risco de fibrose pulmonar é maior e as localizadas, para as quais uma dose alta de iodo radioativo não traz tantos problemas.

Dra. Ana Claudia Latrônico (Médica Assistente Doutora do Serviço de Endocrinologia e Metabologia do HCFMUSP):

Não seria interessante estudar outros exons do gene p53, além daqueles que são classicamente pesquisados?

\section{Dr. Geraldo Medeiros-Neto: \\ Acredito que sim.}

Dr. Idevaldo Floriano (Médico Residente do Serviço de Endocrinologia e Metabologia do HCFMUSP):

E possível se suspeitar de CA insular pela citologia de material obtido por PAAF? Isto me parece importante, no sentido de poder orientar a conduta cirúrgica.

Dra. Rosalinda Camargo (Médica Assistente Doutora do Serviço de Patologia do HCFMUSP):

Eu nunca fiz citologia de CA insular e imagino que viria uma grande quantidade de células em arranjo sólido, ou células isoladas sem formar arranjo folicular e papilífero com pequenas células. Acho que a citologia poderia levantar a suspeita de CA insular.

\section{Dra. Maria Adelaide A. Pereira:}

Na revisão da literatura que fizemos para o estudo desse caso, tivemos a oportunidade de ler dois artigos, um publicado na revista Thyroid e outro no American Journal of Pathology, sobre citologia em CA insu- 
lar $(12,13)$. Os autores afirmam que é possível fazer a suspeita diagnóstica de CA insular em exame citológico de material obtido pela PAAF. A pergunta do Dr. Idevaldo é muito importante, porque é fundamental que o médico saiba se vai ser necessário uma tireoidectomia total acompanhada de limpeza ganglionar. Se houver suspeita de CA insular pela citologia, a programação cirúrgica deve ser diferente daquela adotada nos CAs bem diferenciados.

Dr. Bernardo Léo Wajchenberg (Professor Emérito da Disciplina de Endocrinologia e Metabologia da FMUSP):

Nos carcinomas papilíferos, existe relação entre o grau de anaploidia e a presença de p53?

\section{Dra. Rosalinda Camargo:}

Não sei. Gostaria de insistir que a IHQ para p53 deveria ser feita em todo material de citologia. A positividade poderia orientar para uma conduta cirúrgica mais agressiva.

\section{REFERÊNCIAS}

1. Langhans T. Über die epithelialen Formen der malignen Struma. Virchows Arch (Pathol Anat) 1907;189:69-188.

2. Carcangiu ML, Zampi G, Rosai J. Poorly differentiated ("insular") thyroid carcinoma. A reinterpretation of Langhans "wuchernde Struma". Am J Surg Pathol 1984;8:655-68.

3. Papotti M, Micca B, Favero A, Palestini N, Bussolati $G$. Poorly differentiated thyroid carcinomas with primordial cell component. A group of aggressive lesions sharing insular, trabecular, and solid patterns. Am J Surg Pathol $1993 ; 17: 291-301$.

4. Ashfag R, Vuitch F, Delgado R, Albores-Saavedra J. Papillary and follicular thyrold carcinomas with an insular component. Cancer 1994;73:416-23.

5. Pilotti S, Collini P, Mariani L, Placucci M, Bongarzone I, Vigneri $P$, et al. Insular carcinoma: a distinct de novo entity among follicular carcinomas of the thyroid gland. Am J Surg Pathol 1997:21:1466-73.

6. Albareda $M$, Puig-Domingo $M$, Wengrowicz $S$, Soldevilas J, Matias-Guiu X. Caballero A, et al. Clinical forms of presentation and evolution of diffuse sclerosing variant of papillary carcinoma and insular variant of follicular carcinoma of the thyroid. Thyroid 1998:8:385-91.

7. Stefan KG, Grebe G, Hay ID. Follicular thyroid cancer. Endocrinol Metab Clin N Am 1995:24:761-801.

8. Hassoun AAK, Hay ID, Goellner JR, Zimmerman D. Insular thyroid carcinoma in adolescents. A potentially lethal endocrine malignancy. Cancer 1997:79:1044-8.

9. Sasaki A, Doa T, Kashima K, Yokoyama S, Nakayama I, Noguchi S. Insular component as a risk factor of thyroid carcinoma. Pathol Intern 1996;46:939-46.

10. Godballe C, Asschenfeldt $P$, Jørgensen KE, Bastholt $L$, Clausen PP, Hansen TP et al. Prognostic factors in papillary and follicular thyroid carcinomas: p53 expression is a significant indicator of prognosis, Laryngoscope 1998: 108:243-9.

11. Takeuchi Y, Daa T, Kashima K, Yokoyama S, Nakayama I. Noguchi S. Mutations of p53 in thyroid carcinoma with an insular component. Thyroid 1999:9:377-81.

12. Sironi $M$, Collini $P$, Cantaboni $A$. Fine needle aspiration cytology of insular thyroid carcinoma. A report of four cases. Acta Cytologica 1992;36:435-9

13. Kuhel WI, Kutler DI, Santos-Buch CA. Poorly differentiated insular thyroid carcinoma. A case report with identification of intact insulae with fine needle aspiration biopsy. Acta Cytol 1998;42:991-7.

\section{Endereço para correspondência:}

Maria Adelaide A. Pereira

Disciplina de Endocrinologia e Metabologia

Hospital das Clínicas da Faculdade de Medicina-USP

Av. Dr. Enéas de Carvalho Aguiar, 255

PAMB, $7^{\circ}$ andar - Sala 7037

05403-000 São Paulo, SP 